\title{
DETECÇÃO DE ZONAS DE FUGA D'ÁGUA EM RESERVATÓRIOS, UTILIZANDO TÉCNICAS GEOFÍSICAS (POTENCIAL ESPONTÅNEO)
}

\author{
NELSON ELLERT \\ Departamento de Geologia Econômica \\ e Geofísica Aplicada
}

\author{
WLADIMYR SANCHES \\ Companhia Energética de São Paulo \\ - CESP
}

\begin{abstract}
The SP technique in conjunction with the injection of radioisotopic tracer ${ }^{3} \mathrm{H}$ were used on the Saracuruna Dam (RJ) to determine high infiltration rate zones as well as the average permeability of the dam material. The results indicate the presence of zones of high permeability predominantly concentrated on the right hand side of the dam. SP measurements up to $20 \mathrm{mV}$ were detected in several isolated areas, indicating zones of high permeability which were confirmed independently by the radioactive tracer results.
\end{abstract}

\section{RESUMO}

Levantamentos pelos métodos do potencial espontâneo e de traçadores radioativos foram executados na Barragem de Saracuruna-RJ, com a finalidade de determinar zonas de infiltração, bem como a permeabilidade média, em função das velocidades de deslocamento da nuvem radioativa. Os resultados obtidos permitiram comprovar a existência de vazamento na ombreira direita. Infiltrações ocorrem também pelo fundo da barragem, como indicam os potenciais de até $20 \mathrm{mV}$ aí encontrados.

\section{INTRODUÇÃO}

Percolações de água em barragens são comuns, e previstas nos projetos, mas se forem pronunciadas, acarretam sérios problemas de ordem técnica. Conhecem-se vários exemplos de barragens que nunca chegaram a acumular o volume d'água previsto, porque a permeabilidade das rochas do reservatório e/ou material da barragem foi subestimada.

Quando as percolações são generalizadas não trazem qualquer risco ao empreendimento, comprometendo somente a sua eficácia. Quando porém ocorrem concentrações de fluxo em zonas restritas, podem advir conseqüências gra- ves. As velocidades de infiltração, ao atingirem valores críticos, provocam carreamento de material que poderá, eventualmente, levar ao colapso da barragem. Admite-se que a causa de algumas catástrofes deste tipo tenha sido a existência de áreas de infiltração concentrada, provocando carreamento do corpo da barragem, não detectada em tempo.

Quando a fuga d'água é apreciável, é comumente detectada por um balanço hidrologico da barragem, considerando-se o volume d'água admitido no reservatório, o escoado e o evaporado. Porém este método não define os locais de infiltração e fuga.

Observações do nível d'água em piezô-

Aceito em 16 de junho de 1982. 
metros de controle, bem como a constatação de novas ressurgências de água nas vizinhanças do reservatório e na barragem em si, constituem importantes dados para equacionar o problema. Estes dados, juntamente com informaçōes geológicas sobre a litologia e estrutura da área, tornam possivel delimitar zonas supostamente perigosas. Neste caso, devem ser tomadas medidas corretivas a fim de eliminar ou, pelo menos, reduzir a intensidade do fenômeno. Estas são expressas principalmente sob a forma de colmatação do fundo da represa por material argiloso, ou então a injeção de cimento para formar uma cortina de vedação. Para que medidas adequadas e racionais de prevenção, ou de eliminação de infiltrações possam ser adotadas, é necessário um conhecimento preciso de sua localização.

A delimitação das áreas de fuga d'água é de grande importância para um planejamento racional, técnico e econômico de impermeabilização.

Dentre as várias técnicas utilizadas para identificação dos locais de infiltração, citamos a injeção de corantes sob pressão em furos de sondagem, injeção de traçadores radioativos, etc. Após a injeção do marcador, são feitas observações visuais quando se trata de corantes, ou detecção de radiações quando o material infiltrado for um radiotraçador.

Quanto aos locais de vazamento em barragens, podem ser mencionados: o maciço, as fundações do maciço, as ombreiras e o fundo da represa.

Normalmente os primeiros são investigados detalhadamente durante a construção da barragem, mas o fundo da área represada muitas vezes é relegado a um segundo plano. Contatos litológicos, falhas, pegmatitos, planos de xistosidade, são caminhos preferenciais e pré-existentes para a percolação.

\section{POTENCIAIS ELÉTRICOS ESPONTÁNEOS DE FILTRAÇĀO}

A possibilidade de usar potenciais espontâneos para o estudo de fuga d'água em reservatórios fundamenta-se no fato de que um campo elétrico é gerado pela passagem do fluxo d'água num meio poroso (eletrofiltração). Apesar da existência do fenômeno ser conhecida há muito tempo, a totalidade dos fatores envolvidos no fenomeno e suas naturezas permanecem obscuras. Admite-se que o surgimento desses potenciais elétricos de filtração se deve essencialmente à formação de uma dupla camada iônica de adsorção, no contato das fases sólida/líquida do meio poroso.

Segundo Ward (1966) todos os minerais exibem a formação de uma dupla camada iônica quando em presença de um eletrólito, e, ao que tudo indica, é a estrutura cristalina que permite a predominância de uma carga elétrica negativa na superfície do grão mineral, devido a fenômenos de troca iônica. A carga negativa é neutralizada pela adsorção de cátions do eletrólito, formando-se assim uma dupla camada de cátions. A primeira é fixada na superfície do grão, enquanto que a segunda constitui uma camada difusa. Como os cátions desta camada difusa têm uma certa mobilidade em presença de um fluxo, são parcialmente carreados. Estabelece-se assim um desequilíbrio em termos de cargas iônicas que se traduz por um excesso de carga negativa a jusante.

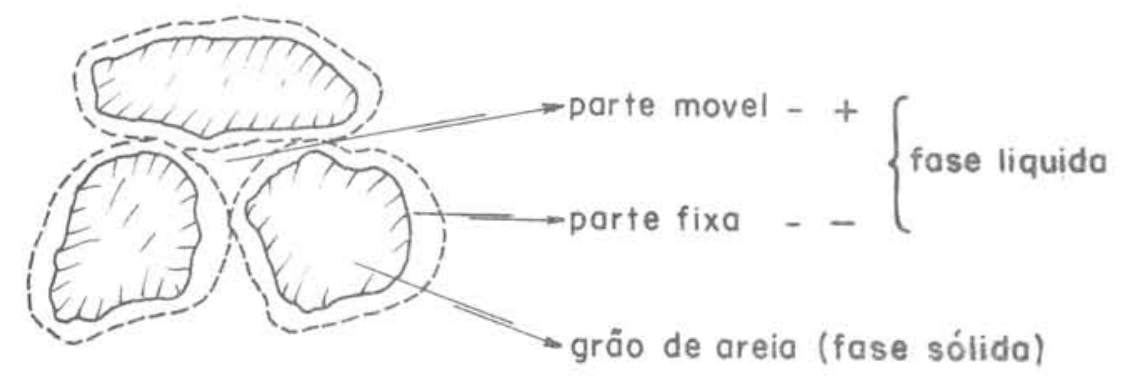

Fig. 1 - Esquema do comportamento das cargas elétricas nas partes móvel e fixa da fase líquida. 
Em consequência desta polarização, surge assim espontâneamente uma diferença de potencial que é conhecida na literatura como potencial espontâneo de filtração.

\section{ENSAIOS EM LABORATÓRIO}

As bases teóricas do potencial de filtração foram inicialmente estabelecidas por Helmholz, que considerou o fluxo de um líquido através de um tubo capilar, chegando à seguinte expressão:

$$
\mathrm{V}=\frac{\delta \epsilon u \mu}{4 \pi} \Delta \mathrm{P}
$$

onde: $\mathrm{V}=$ potencial de filtração

$\delta=$ resistividade do líquido

$\epsilon=$ constante dielétrica do líquido

$v=$ potencial eletrocinético

$\mu=$ viscosidade do líquido

$\Delta \mathrm{P}=$ diferença de carga hidráulica
Pela equação acima, verifica-se que para um determinado tubo-capilar e uma mesma solução a relação $\mathrm{V} / \mathrm{P}=$ constante .

No caso dos meios porosos, os fatores condicionantes dos potenciais são muito mais complicados que em tubos capilares, uma vez que é essencial considerar as variaçōes nas composições granulométricas, nas permeabilidades e porosidades dos meios, na forma e na tortuosidade dos poros, na superfície livre, além de outros fatores como teores de sais dissolvidos nas soluções percolantes.

Muitas discrepâncias nas conclusões de experimentos realizados são, em parte, causadas pelas diferentes condiçōes de ensaio. Parte destas se devem ao potencial de fluxo, potencial este que surge quando dois eletrodos metálicos são submetidos a um fluxo líquido, sendo este potencial independente de potencial de eletrofiltração. Estes potenciais, também chamados de "efeito-moto-elétrico", podem atingir dezenas, até centenas de milivolts.

As medições de potencial de filtração

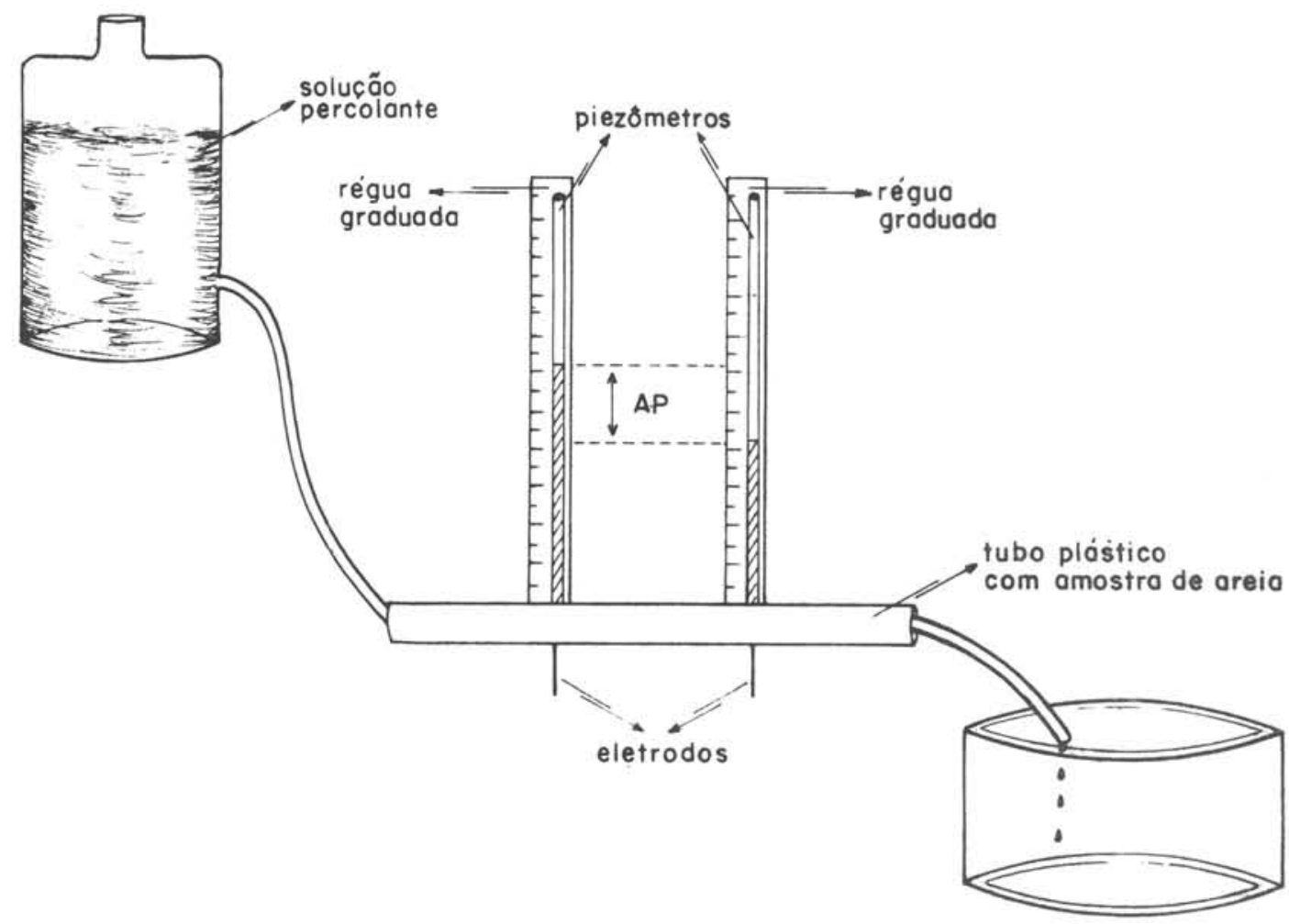

Fig. 2 - Arranjo utilizado em laboratório. 


\section{ELLERT N. SANCHES W}

em laboratório podem ser consideradas confiáveis se forem utilizados eletrodos especiais de pratalcloreto de prata, pois não geram potenciais de fluxo.

Procurando adaptar o arranjo utilizado por Ggilvy Ayed e Bogostovsky (1969) foj construido um modelo, conformé esquematiza. do na figura 2 , utilizando-se porem eletrodos de platina

Para se analisar o comportamento do fenomeno sob diferentes condicōes físicas, foram executadas experiências variando-se os seguintes parâmetros penéncias variando-se os segun

tes pa a mermeabilidade, porosidade (utilizango diferentes fracóes granulométricas)

b : diferentes gradientes de pressão.

c : soluçōes com diferentes teores em sais dissolvidos

A variação da porosidade e permeabilida. de foi obtida pela utilizacâo de amostras de areia com diferentes granulometrias, a saber (a) 105 a $177,(\mathrm{~b}) 177$ a 250 (c) 250 a 297 , (d) 297 a 420 , (e) 420 a 840 , (f) 840 a 1090 , (g) 1090 a 2000 microns.
Estas amostras foram acondicionadas em tubo plástico com $2,5 \mathrm{~cm}$ de giametro e $40 \mathrm{~cm}$ de comprimento. $\mathrm{Na}$ parte mediana, a astados $18 \mathrm{~cm}$ entre si, encontram-se os eletrodos na parte inferior e os piezometros na parte supetior. Os plezômetros foram construidos de tubos de plástico flexivel e transparente, fixos a frente de reguas graduadas, permitindo leituras com exatidẫo de mm.

turas 8 equilibrio era alcançado, inclusive a expulsão ge todo o ar, deixando-se a solução percolar pelo menos 30 minutos antes de se fazer qualquer leitura. Após decorrido este prazo, era feita a medida no milivolumetro e anotado 8 gradiente hidráulico entre os gois étetrodos, definido pelas alturas das colunas diágua dentro dos piezometros. d'iguas medidas foram sempre iniciadas com o maior gradiente hidraulico e depois gradativamente reduzido, a fim de se certificar de que todos os poros do sedimento estivessem perfeitamente saturados.

Os resultados obtidos, conforme gráfico da fig 3 , indicam o aumento d8 potencia em unca do aumento do gradiente hidraulico, em concordancia com aqueles obtidos por Ogivy et alii $(1969)$

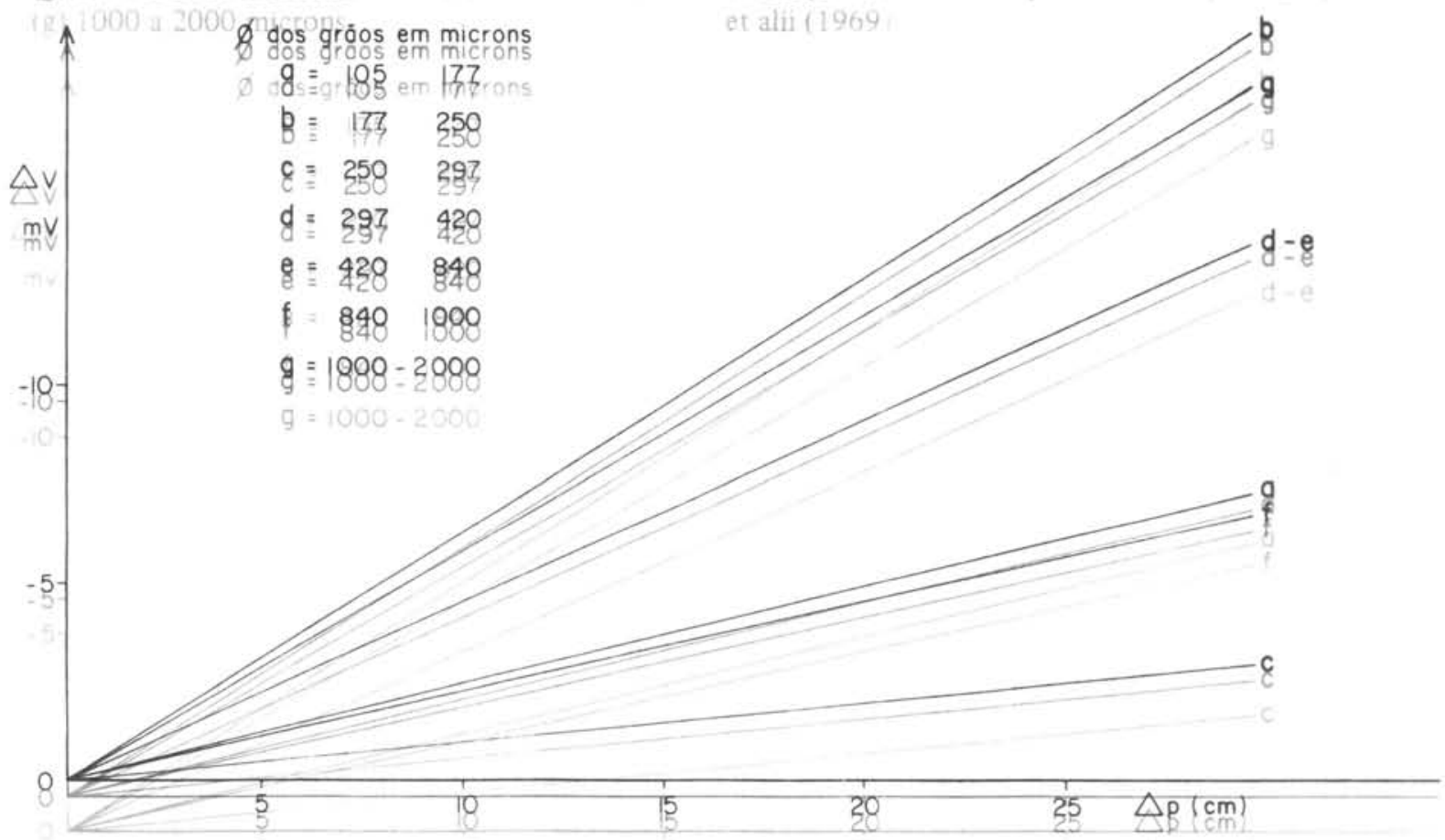

Fig. 3 - Relação $\Delta \mathrm{V} / \Delta \mathrm{P}$ para diferentes granulometrias de areias.

$$
-18=
$$


Para as medições, foram tomados cuidados especiais na determinação acurada dos potenciais estáticos, com o fluido em repouso no meio poroso. Estes valores foram subtraídos daqueles obtidos com fluido em movimento, para obtenção de valores devidos unicamente à filtração.

Foram também realizados ensaios utilizando-se diferentes concentrações em $\mathrm{NaCl}$. A figura 4 representa os resultados obtidos com uma solução de concentração em $\mathrm{NaCl}$ de $10^{-3} \mathrm{~N}$.

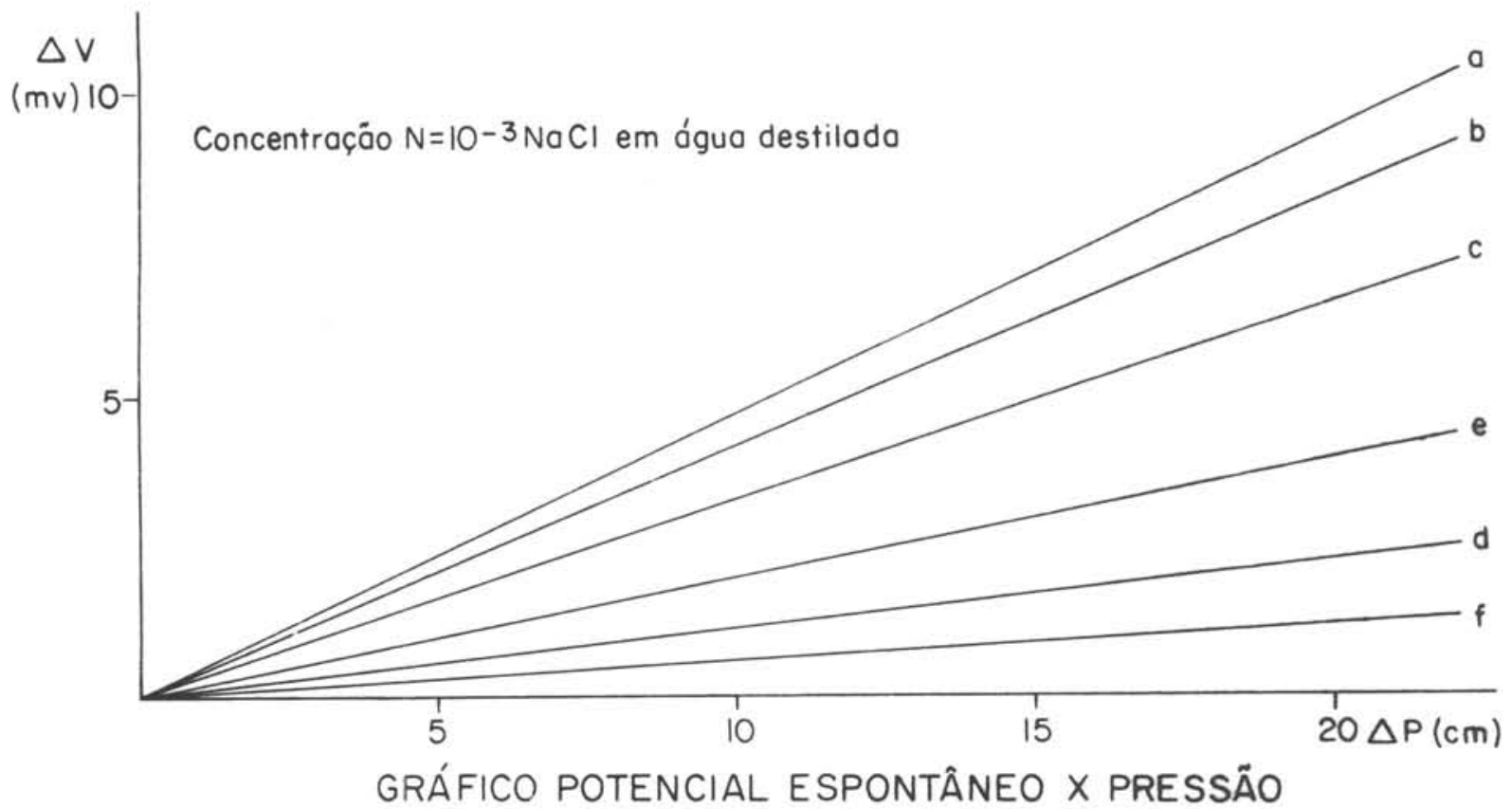

Fig. 4 - Comportamento da relação $\Delta \mathrm{V} / \Delta \mathrm{P}$ utilizando solução $\mathrm{N}=10^{-3}$ de $\mathrm{NaCl}$.

Tanto na figura 3 como na figura 4 , verifica-se que existe uma dependência linear entre $\mathrm{V}$ e $\mathrm{P}$, ou seja o potencial de eletrofiltração, para uma mesma granulometria e uma dada concentração, é proporcional à diferença de pressão, ou seja do fluxo.

Dos ensaios em laboratório algumas conclusões podem ser obtidas:

- o valor do potencial de filtração é afetado de forma acentuada pela permeabilidade do meio filtrante.

- aumentos na carga hidráulica geram aumentos nos vazamentos, por conseguinte, aumentos nos potenciais de filtração.

- em trabalhos práticos de aplicação do método do potencial de filtração, é importante levar em consideração a salinidade da água. Em condições onde a resistividade da água é inferior a $10 \mathrm{ohm} . \mathrm{cm}$, os potenciais de filtração serão, em princípio, muito baixos.

\section{APLICAÇÃO PRÃTICA}

Uma vez verificada a existência de potencial elétrico associado a uma percolação de água por meio poroso, foram feitas observações no campo, estudando-se a Barragem de Saracuruna-RJ, localizada no alto curso do rio Saracuruna, logo após a junção dos Rios Mantiqueira e Pedra Branca, na Serra Estrela, RJ. Esta barragem destina-se ao abastecimento de água da Refinaria Duque de Caxias da Petrobrás. Foi construída entre 1960 e 1962, apresentando desde sua construção vazamentos no fundo e na ombreira direita. 


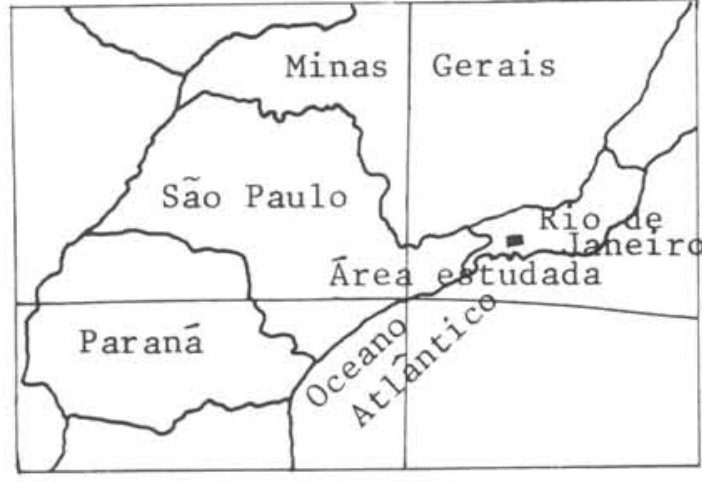

Fig. 5 - Local pesquisado no Estado do Rio de Janeiro.

\section{Geologia Local}

Geologicamente, a região é constituída por migmatitos cobertos por um regolito bastante espesso, onde são comuns matacões e solo pouco consolidado. O fundo do vale contém cascalhos, areias, bem como matacōes. $\mathrm{Na}$ ombreira direita eram muito comuns orifícios tubulares vazios provenientes de sauveiros ativos e inativos, implicando numa acentuada redução do caráter de estanqueidade da ombreira.

\section{Trabalhos de Campo, Equipamentos e Medidas}

Além do barco, teodolitos, etc., foram usados um milivoltímetro eletrônico de alta impedância de entrada e eletrodos do tipo não polarizável, $\mathrm{Cu} / \mathrm{CuSO}_{4}$.

Um eletrodo era mantido fixo na borda da zona inundada, em local saturado, de modo a não haver grande resistência de contato. $\mathrm{O}$ segundo eletrodo era lançado, a partir do barco, ao fundo da represa, aí permanecendo durante as medidas.

$O$ valor de diferença de potencial entre o ponto fixo e a estação de medida era anotado. A presença de correntes telúricas dificultou sobremaneira as medidas. Quando estas se manifestavam de forma muito intensa, as medidas eram interrompidas e reiniciadas no dia seguinte, refazendo-se o último perfil do dia anterior, a fim de se verificar a existência de qualquer variação possibilitando determinar uma sobreposição válida para fins de interpretação.

\section{Interpretação dos Dados de Campo}

Nos trabalhos de campo na represa de Saracuruna foram medidos 8 perfis com 110 pontos de medida aproximadamente.

A posição dos perfis, bem como a dos pontos de medida acham-se assinalados no mapa da figura 7.

Observando-se os perfis obtidos, verifica-se que os pontos mais distantes possuem potencial mais elevado do que o ponto mais próximo, causado pelo "potencial ohmico" (Baeckmann e Schwenk, 1971).

Há assim um gradiente regional de potencial, que, sendo as condições geológicas homogêneas, deve ser constante para toda a área. Valores ou picos anômalos sobre estes perfis devem ser produto da presença de fugas d'água.

Observando-se os valores dos picos, bem como a sua posição no terreno, verifica-se que estes estão distribuídos em locais restritos, quais sejam, áreas de infiltração.

No trabalho de Ogilvy et alii (1969) os valores encontrados são de potencial elétrico negativo. Em nosso caso verificamos que o potencial é positivo. As experiências em laboratório indicaram que o eletrodo mais próximo à entrada d'água possuía potencial positivo em relação ao outro eletrodo, comprovando assim que os locais de infiltração a montante são positivos em relação aos pontos situados a jusante.

\section{TÉCNICAS RADIOISOTÓPICAS}

Posteriormente, o então Instituto de Energia Nuclear da U.S.P., realizou pesquisas objetivando avaliar as grandezas das permeabilidades médias em diferentes pontos, utilizando traçadores radioativos.

Estes ensaios foram aplicados para se determinar as interconexões da água dos furos de sondagem com a dos piezômetros próximos e a da represa.

Os resultados obtidos constam da figura 8 , onde estão representados os pontos que detectaram o aparecimento de soluções radioati- 


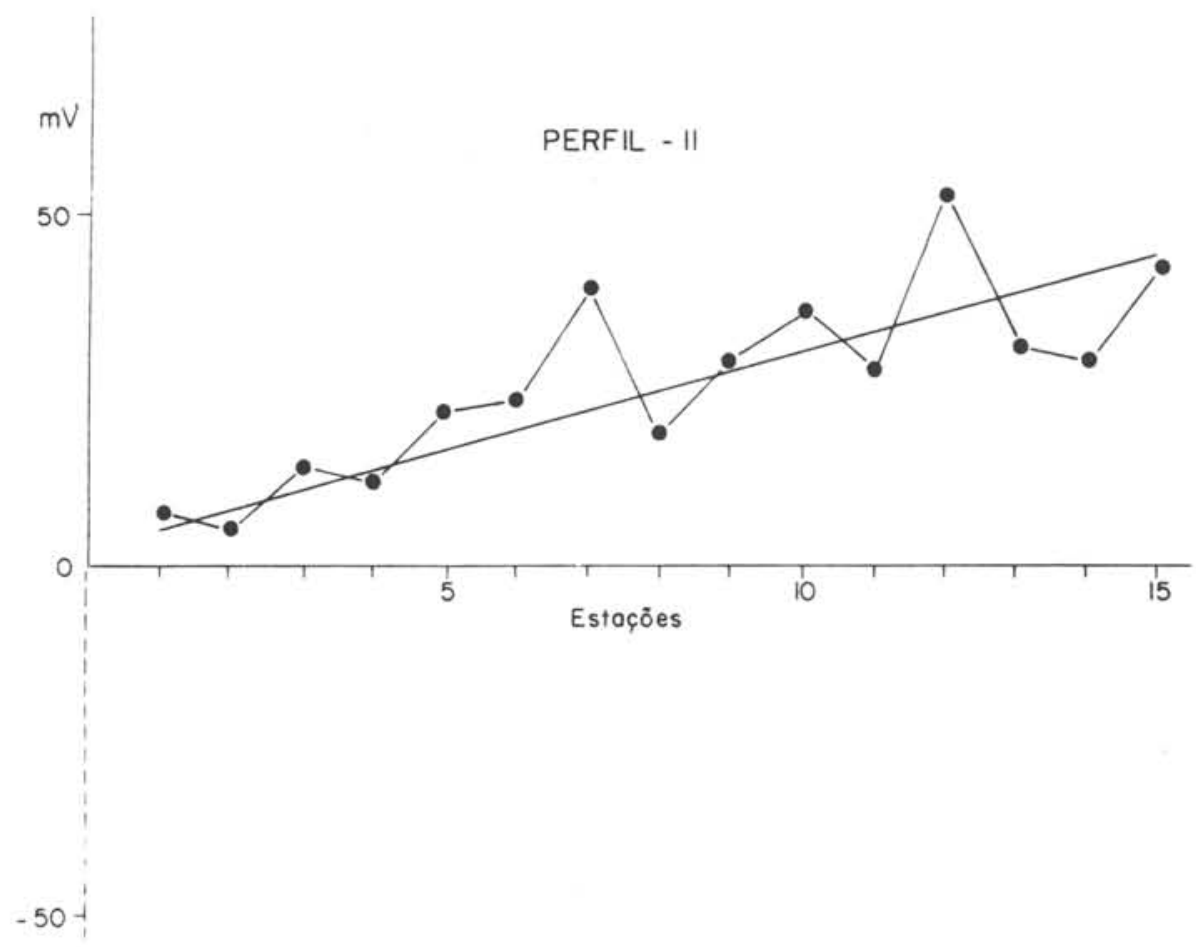

Fig. 6 - Valores medidos no campo ao longo do perfil II.

vas, indicando interconexōes.

Os resultados das seis injeçðes realizadas na ombreira direita permitiam concluir que:

1. Nessa região a infiltração de água é generalizada. Não existe uma fissura localizada, mas sim uma região bastante permeável como revela a figura 8 .

2. O valor médio do coeficiente de permeabilidade, obtido a partir dos dados coletados durante as seis injeções de solução radioativa para a zona ensaiada pertencente a ombreira direita (dentro das hipóteses de cálculo), é $\mathrm{K}_{\text {min }}=8,5 \cdot 10^{-4} \mathrm{~cm} / \mathrm{s}$. Nos cálculos foi levada em conta a velocidade média determinada pelo intervalo de tempo transcorrido entre a injeção de solução radioativa e o de sua detecção que é representada pelo baricentro da curva de variação da concentração em função do tempo. Levando-se em conta apenas o instante de chegada da onda radioativa, obtém-se $\overline{\mathrm{K}}_{\mathrm{min}}=$ $3,5 \cdot 10^{-2} \mathrm{~cm} / \mathrm{s}$, cujo valor não é representativo.

3. A monitoração da água do reservatório mostrou que as atividades detectadas no talude aumentavam com a profundidade. As águas superficiais apresentavam baixa atividade, mostrando claramente que existia um fluxo de partículas ativas dirigido de baixo para cima.

4. Na região do talude submerso onde foram detectadas as atividades, as maiores correspondem à zona dos matacð̃es. Esta região está localizada a vinte (20) metros a montante do Poço IPT-1 e é mostrado na figura 8.

5. A máxima atividade detectada no talude submerso corresponde à injeção realizada no furo SR-20.

$\mathrm{Na}$ ombreira esquerda foram realizadas quatro injeções nos furos SR-12, SR-15 e SR-12. Os resultados mostraram:

1. A zona de infiltração de água na ombreira esquerda é menor que a encontrada na ombreira direita. Na figura 8 observa-se que essa infiltração também é generalizada. Não há, portanto, fissuras localizadas na região ensaiada.

2. O valor médio do coeficiente de permeabilidade da região ensaiada, dentro das hipóteses de cálculo, é $\overline{\mathrm{K}}_{\min }=1,4 \cdot 10^{-4} \mathrm{~cm} / \mathrm{s}$. 


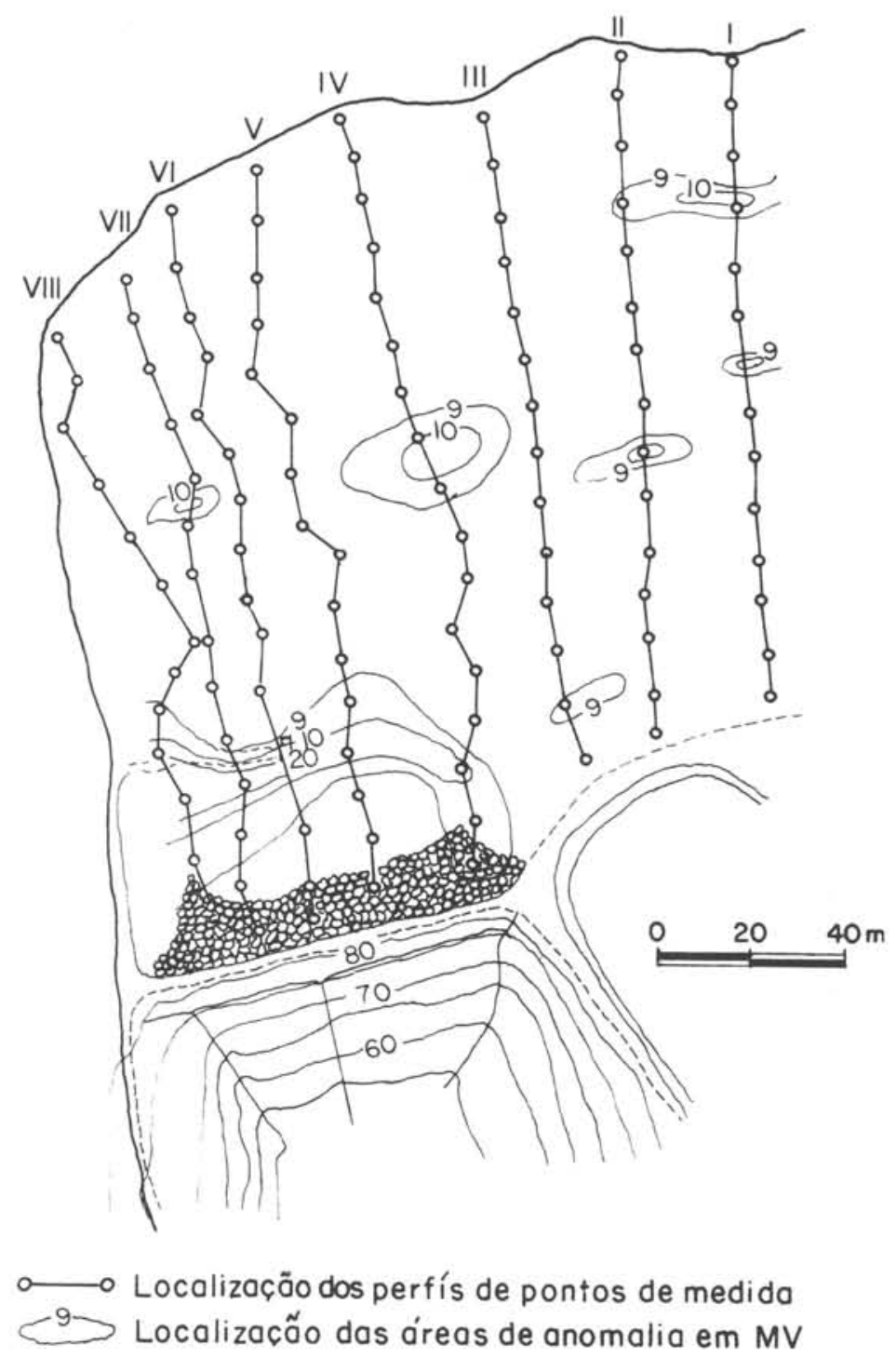

Fig. 7 Mapa da localização das anomalias elétricas.

3. A comparação entre os dois valores médios do coeficiente de permeabilidade mínimo mostra que a região ensaiada pertencente à ombreira direita é aproximadamente sete vezes mais permeável que a região ensaiada pertencente à ombreira esquerda.

4. Comparando-se os valores calculados a partir do instante da chegada da onda radioativa nos furos de amostragem, observa-se também a diferença de um fator 7 entre os dois coefi- cientes de permeabilidade médio $\left(\mathrm{K}_{\text {direita }}=\right.$ $3,5 \cdot 10^{-2} \mathrm{~cm} / \mathrm{s} e^{K}$ esquerda $=5,4,10 \mathrm{~cm} / \mathrm{s}$ ).

5. A máxima atividade detectada no talude submerso corresponde à região assinalada na figura no 8 e foi proveniente da injeção realizada no furo SR-13.

6. Semelhantemente ao verificado na ombreira direita, as atividades detectadas no talude submerso aumentam com a profundidade. 
DETECÇÃO DE ZONAS DE FUGA D'AGUA EM RESERVATORIOS, UTILIZANDO TÉCNICAS GEOFISICAS (POTENCIAL ESPONTANEO)

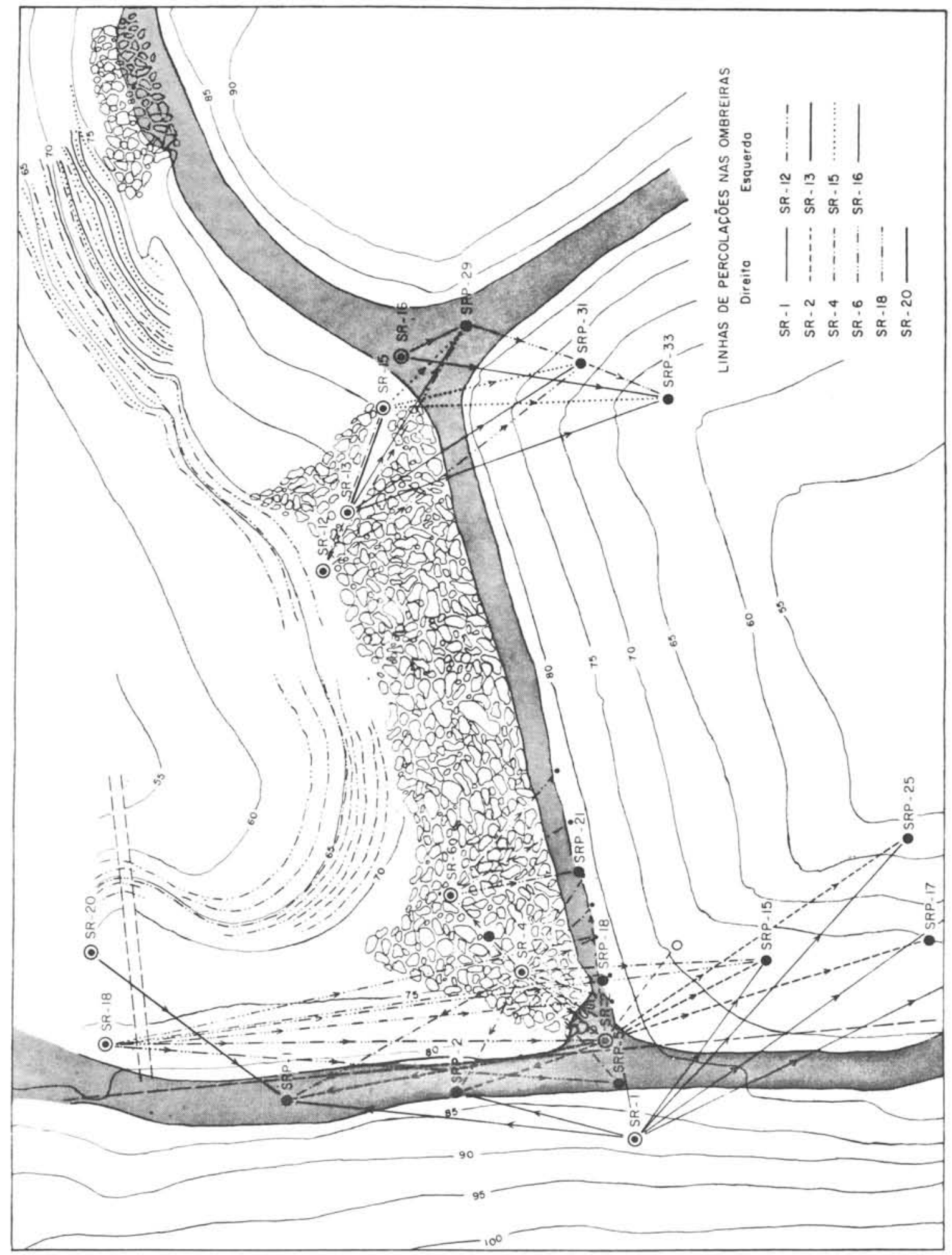




\section{CONCLUSÕES GERAIS}

Observando-se as figuras 7 e 8 , verifica-se uma boa correlação entre os dados obtidos pela técnica de injeção de soluções contendo radioisótopos e o método do potencial espontâneo. Os valores de potencial elétrico obtidos na margem direita são bem mais elevados que aqueles da margem esquerda, onde elevadas permeabilidades foram detectadas pelo levantamento de radiações.

Algumas anomalias de potencial espontâ- neo também foram verificadas mais a montante da barragem, indicando uma área de infiltração não detectada pela segunda técnica.

As técnicas de medida do potencial de filtração são rápidas e pouco dispendiosas, não requerendo a existência de furos para a criação de campos cuja distribuição se deseja investigar.

Os trabalhos de campo, realizados com auxílio de uma pequena equipe e equipamentos pouco dispendiosos, revelaram a aplicabilidade do método na identificação dos pontos de infiltração em fugas d'água de reservatórios.

\section{REFERENCIAS BIBLIOGRẢFICAS}

BAECKMANN, W.V. e SCHWENK, W. - Handbuch des Kathodischen Korrosionsschutzes, Verlag Chemie Gmbh 1971.

GUIZERIX, J. - "Localisation des fuites sur un grand reservoir à l'aide des traceurs radioactifs" Isotopes in Hidrology, Vienna, 1966.

KAUFMANN, W.J. - "Application of ${ }^{3} \mathrm{H}$ tracer to canal seepage measurements". Proc. Symp. Vienna, 1962, 83-94.

OGILVY, A.A.; AYED, M.A. e BOGOSLOVSKY, V.A. - "Geophysical Studies of Water Leakages from Reservoirs" Geoph. Prosp. Vol. XVIII, (1), 1969.

SAVERWEIN, K. - "Flow of a stream through a reservoir" Isotopes in Hydrology, Proc. Symp., Vienna, 1966, IAEA, 697.

SANCHES, W. - Relatório interno do Instituto de Energia Atômica, S.P., 1966.

SATO, M. e MONNEY, H.M. - 1960 "The Electrochemical Mechanism of Sulfide Self-Potencials". Geophysics. Vol. XXV, (1).

WARD, S.H. - 1966 "Mining Geophysics". Vol. II. SEG Society of Exploration Geophysicists, U.S.A. 